\title{
Pathways of Endodontic Fear in Different Age Groups for Iraqi Endodontic Patients
}

\author{
Hashim M. Hussein
}

B.D.S., M.Sc., Endodontist, Department of Endodontic Dentistry, Al-Shiekh Omar specialized dental center, Ministry of Health. Nooruldeen A. Saeed

B.D.S., M.Sc., Endodontist, Department of Endodontic Dentistry, Al-Shiekh Omar specialized dental center, Ministry of Health.

\author{
Iman M. Al-Zaka
}

B.D.S., M.Sc., Assistant Professor, Department of Conservative Dentistry, College of Dentistry, University of Al-Mustansiriyah.

\begin{abstract}
Background: Fear, anxiety and phobia are major complications for both patient and dental care providers despite the technological advances that have made dentistry less painful and less uncomfortable. This study aimed to identify the most common pathways of fear related to root canal treatment in different aged groups for both genders.

Materials and methods: The study sample consisted of (800) patients were selected, aged (20-59) years old from patients attending the Al-Shiekh Omar specialized dental center. The questionnaires of pathways of endodontic fear were prepared and translate from English to Arabic languages by certified translator and were filled by patients themselves without any help from endodontists. Patients with mental disabilities, those who only had surgical root canal treatment, those below 20 years and above 59 years old, and those not understand Arabic language were excluded.

Results: The most commonly reported pathway for fear and anxiety with endodontic procedures was the cognitive (32.9\%) followed by the informative, parental, verbal, and vicarious pathways $(29 \%, 25 \%, 6.7 \%, 6.4 \%)$ respectively. Also, the result showed that the informative pathway appeared higher than other pathways in groups $(1,2)$; while cognitive pathway appeared higher than other pathways in groups $(3,4,5,6,7,8)$. The patients in all groups showed the percentage of direct endodontic fear pathway was less than indirect pathway, where the indirect pathway was (65\%) while direct pathway was (35\%) totally. The result of the study showed that females had higher percentage (59.3\%) of endodontic fear than males $(40.7 \%)$ generally.

Conclusion: The present study showed that different pathways appear to be adopted by different age groups, indicating the importance of customizing strategies in the management of fear and anxiety related to root canal treatment. Fear of root canal treatment is mostly influenced by the cognitive pathway.
\end{abstract}

Keywords: Fear, phobia, cognitive pathway, informative pathway, age.

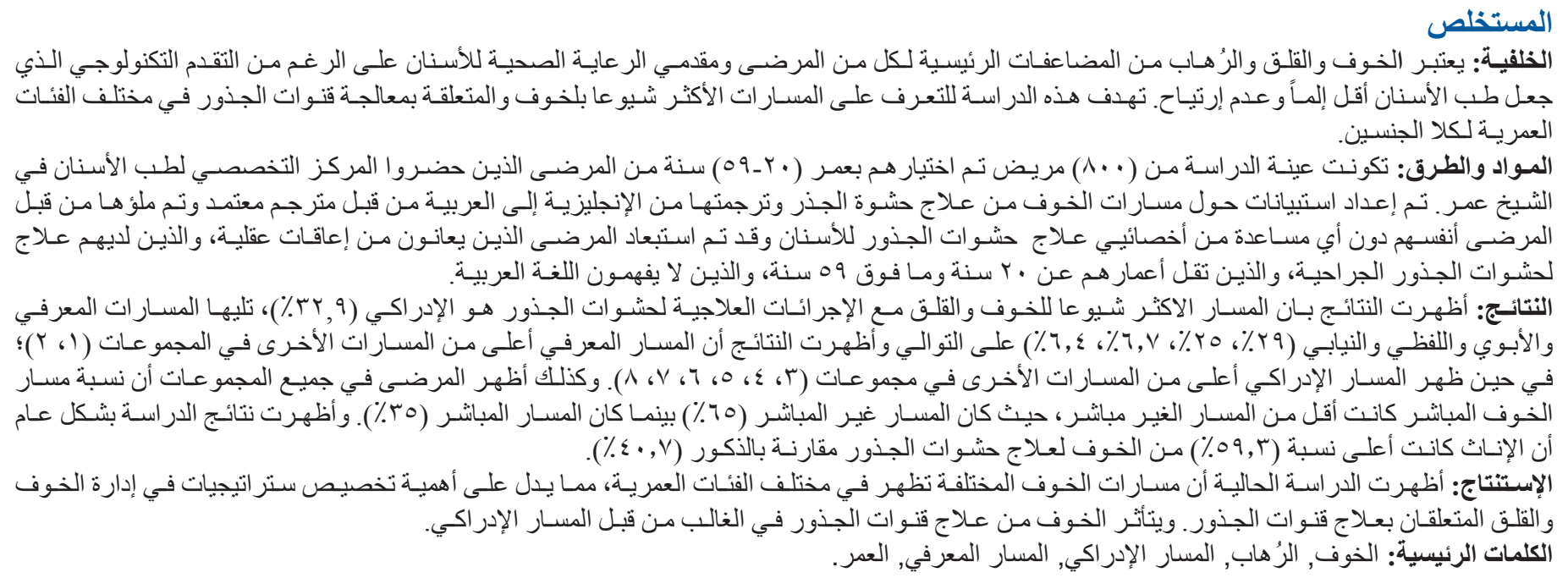

\section{INTRODUCTION}

Generally fear is defined as an individual's response to a real threatening event or dangerous situation to protect his or her life ${ }^{(1,2)}$. An existing specific stimulus like injection or drilling can provoke dental fear immediately ${ }^{(3-5)}$. While dental anxiety refers to patient's specific reaction toward stress associated with dental treatment in which the stimulus is unknown, vague or not present at the moment $(5,6)$. Regardless, in both these situations the patient's emotional reactions could be practically similar ${ }^{(3)}$.

High levels of dental fear and anxiety have been reported to be major reasons for patients delaying or cancelling dental appointments ${ }^{(7)}$. Furthermore, treating anxious patients might take more time; it is hard to manage them during the procedure and they are often unsatisfied with their treatment ${ }^{(\mathbf{8}, \mathbf{9})}$.

Current literature appears to indicate that fears and the pathways involved can differ among individuals ${ }^{(10,11)}$. Although several studies have been conducted on the perception of dental fear and anxiety in different regions of the world (12-16).

Dentists do not usually screen dental fear. A study in England showed that only $20 \%$ of dentists 
who were interested in treating patients with dental fear, had used a screening method to evaluate their patient's level of fear ${ }^{(17)}$. Prior to treatment, dentists should be able to detect patient's level of fear so they can use appropriate management options ${ }^{(3)}$.

Rachman in 1977 was one of the first to look at the pathways of fears and anxiety, proposing that there were three pathways people acquire fears by: conditioning, vicarious and informative.

Years later, Ost and Hugdahl in 1981, 1983, 1985 analyzed multiple pathways of fear (Phobic Origins Questionnaire), to evaluate fear of social phobia, agoraphobia, and simple phobias. It was reported that those who had conditioned experiences (cognitive pathway) had bodily responses to fear.

Five pathways related to dental fear have been recognized: conditioning, parental, informative, verbal threat, and visual vicarious. The conditioning pathway occurs as a result of direct dental traumatic experiences, the parental pathway relates to dental fear learned from parents/guardians, the informative pathway is related to fearful experiences learned/ heard from others, the verbal threat pathway uses the dental environment as punishment for bad behavior in children, and the visual vicarious pathway is caused by fear-inducing dental situations seen in the media ${ }^{(10}$, 22). Patients may have one or more of these pathways when expressing fear and anxiety ${ }^{(23)}$.

\section{MATERIALS AND METHODS}

This study was done in Baghdad city. The study was open for a period of 6 months and ended April 2016. All participants was visited the endodontic department of Al-Shiekh Omar specialized dental center and were invited to participate in the study if they met the inclusion criteria. The total number of participants was (800) and divided into 8 groups as shown in Table (1).

Table (1): Distribution of the population sample.

\begin{tabular}{|l|l|l|}
\hline Group 1 & 100 males & 20-29 years \\
\hline Group 2 & 100 females & $20-29$ years \\
\hline Group 3 & 100 males & $30-39$ years \\
\hline Group 4 & 100 females & $30-39$ years \\
\hline Group 5 & 100 males & $40-49$ years \\
\hline Group 6 & 100 females & $40-49$ years \\
\hline Group 7 & 100 males & $50-59$ years \\
\hline Group 8 & 100 females & $50-59$ years \\
\hline
\end{tabular}

For inclusion, the participants were directly asked whether they had undergone a primary root canal treatment, had root canal retreatment or were treatment planned to have a root canal treatment. Further all participants had to be able to remember their root canal treatments experience.

Participants with mental disabilities, who never had a root filling (not planned to have a root canal treatment), had only surgical treatment, under the age of 20 or above 59 years old, and those who could not understand Arabic (identified by directly asking patient before offering the survey) were excluded.

All questionnaires of endodontic fear pathways were prepared and translated from English to Arabic languages by certified translator. All participants were provided with an information sheet (Questionnaire) and requested to provide informed consent. No intervention was provided to the participants to help them answer the questionnaire.

The first section of the survey questionnaire included personal questions (age and gender), number of times for visiting the endodontic clinic, reason for not visiting (postponing) the endodontic clinic, and also whether the patient was having primary root canal treatment or retreatment.

While the second section was a modification of the first part of 'Phobic Origins Questionnaire' labelled 'A. ONSET OF PHOBIA' created by Ost and Hugdahl in $\mathbf{1 9 8 1}$ for fear and anxiety response patterns (pathways); which consisted of five questions, and each of one refer to type of pathway of fear as shown in Table (2). The patient may have more than one type of pathways.

Descriptive analysis was used in order to analyze and assess the results of the study. 
Table 2: Second section of questionnaire (pathways of endodontic fear).

\begin{tabular}{|c|}
\hline Types \\
\hline Cognitive (conditioning) \\
\hline Informative \\
\hline Parental \\
\hline Verbal threat \\
\hline Vicarious
\end{tabular}

\section{RESULTS}

The result of the study showed that $(60.4 \%)$ of patients had previous endodontic treatment while (39.6\%) of patients hadn't have previous endodontic treatment as shown in Table (3).

The majority of the subjects (55\%) admitted that they were seek endodontic treatment only when there is pain while $(25.3 \%)$ were seek endodontic treatment sometimes occasionally, $(12.1 \%)$ were seek endodontic treatment every 6 months, while $(7.6 \%)$ were seek endodontic treatment every one year as shown in Table (4).

The most common reason given by the participant $(36.4 \%)$ for not attending the endodontic clinic regularly was "cost" while $(32.8 \%)$ thought that "limited time" prevent them from attending endodontic clinic, (18.1\%) of the subjects delayed or avoided treatment because of "dental fair" while the remaining samples (12.8\%) didn't seek treatment because (there is no need) as shown in Table (5).

The patients in all groups showed a variety of pathways to acquire endodontic fear generally. The result appeared that $(32.9 \%)$ of participant indicates that the cognitive pathway caused them to become fearful of endodontic treatment as the most common pathway, (29\%) indicate that they acquire their fear from informative pathway, while $(25 \%)$ was parental

\section{Questions}

$$
\text { past? }
$$

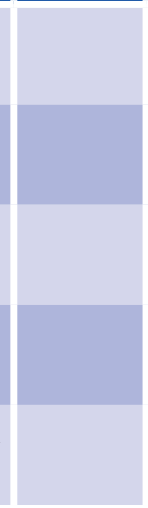

Table (3): Percentage of patients with previous endodontic treatment.

\begin{tabular}{|c|c|c|}
\hline Groups & Yes (\%) & No (\%) \\
\hline G1 & 65 & 35 \\
\hline G2 & 46 & 54 \\
\hline G3 & 47 & 53 \\
\hline G4 & 64 & 36 \\
\hline G5 & 54 & 46 \\
\hline G6 & 69 & 31 \\
\hline G7 & 67 & 33 \\
\hline G8 & 71 & 29 \\
\hline Total & 60.4 & 39.6 \\
\hline
\end{tabular}


Table (4): Percentage of patient's admission to endodontic clinic.

\begin{tabular}{|c|c|c|c|c|}
\hline Groups & Every $\mathbf{6}$ month (\%) & Every year (\%) & Sometimes (\%) & When there is pain (\%) \\
\hline G1 & 15 & 7 & 25 & 53 \\
\hline G2 & 7 & 9 & 23 & 61 \\
\hline G3 & 11 & 9 & 23 & 57 \\
\hline G4 & 9 & 5 & 24 & 62 \\
\hline G5 & 13 & 7 & 29 & 51 \\
\hline G6 & 17 & 11 & 28 & 44 \\
\hline G7 & 15 & 5 & 22 & 58 \\
\hline G8 & 10 & 8 & 28 & 54 \\
\hline Total & 12.1 & 7.6 & 25.3 & 55 \\
\hline
\end{tabular}

Table (5): Percentage of patient's reasons for postponing the attending of endodontic clinic regularly.

\begin{tabular}{|c|c|c|c|c|}
\hline Groups & High cost (\%) & Limited time (\%) & No need (\%) & Dental fair (\%) \\
\hline G1 & 41 & 22 & 31 & 6 \\
\hline G2 & 15 & 35 & 9 & 41 \\
\hline G3 & 32 & 52 & 7 & 24 \\
\hline G4 & 42 & 28 & 6 & 14 \\
\hline G5 & 29 & 45 & 12 & 14 \\
\hline G6 & 51 & 27 & 20 & 16 \\
\hline G7 & 36 & 28 & 9 & 21 \\
\hline G8 & 45 & 25 & 12.8 & 18.1 \\
\hline
\end{tabular}

Table (6): Percentage of patient's endodontic fear pathways.

\begin{tabular}{|c|c|c|c|c|c|}
\hline Groups & $\begin{array}{c}\text { Cognitive } \\
(\%)\end{array}$ & $\begin{array}{c}\text { Informative } \\
(\%)\end{array}$ & $\begin{array}{c}\text { Parental } \\
(\%)\end{array}$ & $\begin{array}{c}\text { Verbal threat } \\
(\%)\end{array}$ & $\begin{array}{c}\text { Vicarious } \\
\text { (\%) }\end{array}$ \\
\hline G1 & 20.4 & 34.4 & 24.8 & 8.9 & 11.5 \\
\hline G2 & 29.5 & 37.1 & 24.2 & 5.3 & 3.8 \\
\hline G3 & 29.5 & 25 & 27.7 & 12.5 & 5.4 \\
\hline G4 & 40.1 & 27.1 & 20.3 & 2.9 & 9.7 \\
\hline G5 & 31.9 & 27.8 & 29.2 & 6.9 & 4.2 \\
\hline G6 & 35.5 & 34.2 & 23.7 & 1.3 & 5.3 \\
\hline G7 & 36.8 & 19.3 & 33.3 & 8.8 & 1.8 \\
\hline G8 & 36.2 & 25.4 & 22 & 9.6 & 6.8 \\
\hline Total & 32.9 & 29 & 25 & 6.7 & 6.4 \\
\hline
\end{tabular}




\section{Bar chart for percentage of e of endodontic fear pathways}

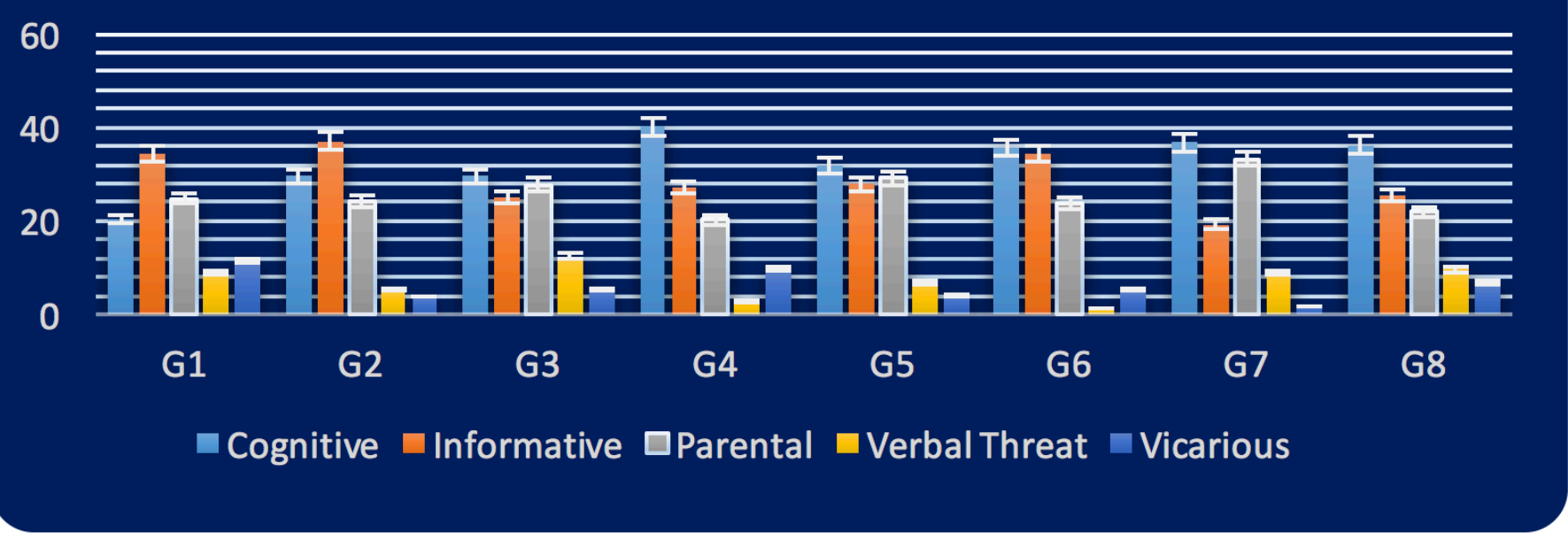

Figure (1): Bar chart graph for Percentage of patient's endodontic fear pathways

Table (7): Percentage of patient's direct and indirect endodontic fear pathways.

\begin{tabular}{|c|c|c|}
\hline Groups & Direct pathway (\%) & Indirect pathway (\%) \\
\hline G1 & 37.2 & 62.8 \\
\hline G2 & 29.5 & 70.5 \\
\hline G3 & 29.5 & 70.5 \\
\hline G5 & 40.1 & 59.9 \\
\hline G6 & 31.9 & 68.1 \\
\hline G7 & 35.5 & 64.5 \\
\hline G8 & 36.8 & 63.2 \\
\hline Total & 36.2 & 63.8 \\
\hline
\end{tabular}

Table (8): Percentage of patient's endodontic fear pathways in males and females.

\begin{tabular}{|c|c|c|c|c|c|c|}
\hline Groups & Cognitive (\%) & Informative (\%) & Parental (\%) & Verbal Threat (\%) & Vicarious (\%) & Total (\%) \\
\hline Males & 29 & 27.3 & 28.5 & 9.1 & 6.1 & 40.7 \\
\hline Females & 35.9 & 30.2 & 22.3 & 4.8 & 6.7 & 59.3 \\
\hline
\end{tabular}

\section{DISCUSSION}

Endodontic fear is a major concern as it can often lead to avoidance of the dentist and delay in requesting advice or treatment. Further management of consenting patients may be difficult because of the difficulty in understanding the nature or cause of fear $(13,15,24)$.

It was reported that out of the various dental procedures, patients were most fearful of endodontic treatment ${ }^{(24)}$. Endodontic fear may be multifactorial, and hence, determination of endodontic patient fear requires analysis of the multiple pathways through which fear develops ${ }^{(22,25,26)}$. A two-point scale (yes and no) was utilized for this study to determine the pathways of fear with endodontic treatment.

The present study looks to understand the origins (pathways) of endodontic fear in different age groups of patients attending the endodontic department of Al-Shiekh Omar specialized dental center.

The current study showed that the cognitive pathway seemed to have a greater influence on the perception of endodontic fear among participants than other pathways generally, and this finding was similar to the result that found by Ost and Hugdahl in 1981; Carter et al. in 2015. This can indicated that patients were most fearful of pain from past experiences where patients found endodontic therapy highly stressful, on par with oral surgery procedures 
(27). In addition, that some of the personal comments indicated that fear could be due to other reasons not related to the actual procedure.

Also, the result showed that the cognitive pathway appeared higher in patients with age between (30-59) years because these groups have enough time to accumulate previous endodontic fear experiences while informative pathway appeared higher in twenties because these patients not have enough time to accept and affect from other persons experience with endodontic treatment.

The patients in all groups showed the percentage of direct endodontic fear pathway was lessor than that of indirect pathway, and can be related to that the direct pathway represent the single effect of cognitive pathway only (direct endodontic traumatic experiences) while indirect pathway represent the total effect of informative, parental, verbal threat, vicarious totally (indirect effect relates to endodontic fear learned from others ex: parents/guardians, friends). This result was agreed with Murray and

\section{Foote in 1979.}

The result of the study showed that females had higher percentage of endodontic fear than males generally and this agreed with Carter et al. in 2015. This can related to the nature of Iraqi females in comparison to Iraqi males whose have the ability to withstand and hide pain.

Determining why endodontic patients feared from dentist was important in treatment planning and managing patients. The use of pretreatment endodontic fear questionnaires may help to identify the cause of patient's fear; this can aided the practicing dentist in managing patients effectively.

The present cross-sectional study has been conducted on a limited population who referred to Sheikh Omar specialized dental center during the study period. These patients had lower economical and educational levels; therefor studies on larger populations are needed to reveal the accurate pathways of endodontic fear in the society.

\section{REFERENCES}

1. Bay EJ, Algase DL. Fear and anxiety: a simultaneous concept analysis. Nurs Diagn. 1999; 10: 103-11

2. Arslan S, Erta E, Ülker M. The relationship between dental fear and sociodemographic variables. Erciyes Med J. 2011; 33:295-300.

3. Milgrom P, Weinstein P, Getz T. Treating fearful dental patients: A patient management handbook, $2^{\text {nd }}$ ed. Seattle: University of Washington 1995.

4. Aartman IHA, van Everdingen T, Hoogstraten J, Schuurs AHB. Self-report measurements of dental anxiety and fear in children: a critical assessment. ASDC J Dent Child.
1998; 65: 252-258.

5. Jaakkola $\mathrm{S}$, Rautava $\mathrm{P}$, Alanen $\mathrm{P}$, Aromaa $\mathrm{M}$, Pienihäkkinen $\mathrm{K}$, Räihä $\mathrm{H}$, et al. Dental fear: One single clinical question for measurement. Open Dent J. 2009; 3:161-166.

6. Humphris GM, Dyer TA, Robinson PG. The modified dental anxiety scale: UK general public population norms in 2008 with further psychometrics and effects of age. BMC Oral Health. 2009; 9:20.

7. De Jongh A, van der Burgh J, van Overmeir M, Aartman I, van Zuuren FJ. Trauma-related sequelae in individuals with a high level of dental anxiety. Does this interfere with treatment outcome? Behavioural Research and Therapy. 2012; 40:1017-1029.

8. Quteish Taani DS. Dental anxiety and regularity of dental attendance in younger adults. J Oral Rehabil. 2002; 29:604608.

9. Erten H, Akarslan ZZ, Bodrumlu E. Dental fear and anxiety levels of patients attending a dental clinic. Quintessence Int. 2006; 37:304-310.

10. Carter A, Carter G, Boschen M, et al. Pathways of pain in dentistry: a review. World J Clin Cases. 2014; 2:642-653.

11. Carter A, Carter G, George R. Pathways of fear and anxiety in endodontic patients. Int Endod J. 2015; 48:528-532.

12. Domoto PK, Weinstein P, Melnick S, et al. Results of a dental fear survey in Japan: implications for dental public health in Asia. Community Dent Oral Epidemiol. 1988; 16:199-201.

13. Moore R, Birn H, Kirkegaard E, et al. Prevalence and characteristics of dental anxiety in Danish adults. Community Dent Oral Epidmiol. 1993; 21:292-296.

14. Schwarz E, Birn H. Dental anxiety in Danish and Chinese adults-a cross-cultural perspective. Soc Sci Med. 1995; 41:123-130.

15. Nicolas E, Collado V, Faulks D, et al. A national Cross sectional survey of dental anxiety in the French adult population. BMC Oral Health. 2007; 7:1-7.

16. Nagel T, Robinson G, Trauer T, Condon J. An approach to treating depressive and psychotic illness in indigenous communities. Aust J Prim Health. 2008; 14:17-24.

17. Armfield JM. Australian population norms for the Index of Dental Anxiety and Fear (IDAF-4C). Australian Dental Journal. 2011; 56:16-22.

18. Rachman S. The conditioning theory of fear acquisition: a critical examination. Behavioural Research and Therapy. 1977 ; 15:375-387.

19. Ost LG, Hugdahl K. Acquisition of phobias and anxiety response patterns in clinical patients. Behavioral Research and Therapy. 1981; 19:439-447.

20. Ost LG, Hugdahl K. Acquisition of agoraphobia, mode of onset and anxiety response patterns. Behavioral Research and Therapy. 1983; 21:623-631.

21. Ost LG, Hugdahl K. Acquisition of blood and dental phobia and anxiety response patterns in clinical patients. Behavioral Research and Therapy. 1985; 23:27-34.

22. Field AP, Ball JE, Kawycz NJ, Moore H. Parent-child relations and the verbal information pathway to fear in children: two preliminary experiments. Behavioural and Cognitive Psychotherapy. 2007; 35: 473-486.

23. Australian Government. Australian Public Service Commission Multicultural Plan: 2013-15. Australia: Australian Public Service Commission; 2013.

24. Oosterink FM, de Jongh A, Hoogstraten J. Prevalence of dental fear and phobia relative to other fear and phobia 
subtypes. Eur J Oral Sci. 2009; 117(2):135-143.

25. Rachman S, Lopatka C. Do fears summate?-III. Behavioural Research and Therapy. 1986; 24: 653-660.

26. Coelho MC, Purkis H. The Origins of specific phobias: Influential theories and current perspectives. Review of General Psychology. 2009; 13:335-348.
27. Murray EJ, Foote F. The origins of fear of snakes. Behar. Res. Ther. 1979; 17:489-493.

28. Wong M, Lytle WR. A comparison of anxiety levels associated with root canal therapy and oral surgery treatment. Journal of Endodontics. 1991:17:461-465. 